\title{
Sustainable Development Requires an Integrated Design Discipline to Address Unique Problems
}

\author{
Rui H. Dos Santos Martins
}

143 Donnelly Rd, Arcadia Vale NSW, Australia

rui@dsmartins.com

\begin{abstract}
Sustainable development has taken centre stage in our global conscience. Until recently, we have been focused on economic prosperity, driven by the mechanistic worldview of the scientific method. Once the cracks appeared, as a society, we have been looking for a deeper meaning and approach to life. Through a literature review, the paper proposes that current 'experts', using the engineering profession as an example, are not able to address the wicked problems confronting us, since they prevail within the reductionist mode of knowledge production. We need design thinkers - who are natural systemic practitioners -to solve systemic problems, which is characterised by sustainable development.
\end{abstract}

A future second paper will draw on the behavior of non-linear, complex adaptive systems as self-organizing emergence at the edge of chaos and re-interpret the design thinking process in a way which encompasses the intuitive, non-linear and qualitative way in which sustainable development problems need to be addressed.

Keywords: design thinking; sustainable development; systems thinking.

\section{Introduction}

Until recently, our global society has focused mainly on economic development. 'Professional practice' has assisted in this endeavour by delivering products and services so that entrepreneurs and business in general is able to achieve this single objective. At the same time, there is an awareness that more problems were often being created at another level, treating business as separate from the environment.

Professionals/experts are trained to solve the problem given to them by their 'client'. If an issue is not defined by the brief then it is not to be addressed - 'it is out of scope!' There are endless examples where various professional groups are on record as having created more problems in the process of solving another problem. Simplification only examines issues at a superficial level and specialisation examines a square inch of detail of the whole picture - both therefore only examine limited aspects of the issues at hand. We need a new perspective to see reality differently (Martin, 2007). Design Thinking promises to do this.

Sustainable development is not a new concept. Yet we are now increasingly aware as a

society of the implications and possible consequences of any form of development that is not sustainable. This implies a serious deconstruction and reconfiguration of many aspects of our lives, in particular, how can experts ensure that they are responsibly delivering sustainable solutions to the community, the market and society?

The objective of this paper is to outline the proposition that 'design thinking', as a systemic process, is an essential discipline that is able to solve complex and messy problems such as sustainable development.

\section{Historical Context}

The history of professional development is a complex story. Through a combination of socio-political, economic, religious and cultural forces (Seitz, 1992), a science emerged that emphasised a mechanistic attitude to nature and whose advocates included Bacon, 
Descartes, Galileo, Newton and Mersenne (Shapin, 2008).

Although in many respects we have moved far away from the Newtonian method of solving problems, our professions remain focused on the search for certainty. This is underpinned by the mechanistic and deterministic modern scientific method and epistemology in the name of material progress and for the betterment of humanity. Through reductionist research, individual professions, as various authors have suggested (Berman, 1981, Kuhn et al., 2000, Shapin, 1996), still frame problems at a distance from the object of inquiry and its highly selected bounded context. This implies that we as a culture in the West still exist in varying degrees under the epistemological grip of the mechanistic paradigm.

The fundamental axiom of modern professions is based on prediction and control, which is a view held by critical theorists such as Adorno, Horkheimer, Habermas and Weber (Leiss, 1994). Furthermore, professional knowledge, as suggested by Foucault (1980), is a contest for power, since it is power, rather than fact about reality, that makes things true. This results in the empowerment of experts and the exclusion of the community. Humans and their relationship to the environment (context/structure) are the object of study. Professional objectivity, reasoning, model building and empirical testing focus on efficiency and technological advances as the underpinning of development and progress, in which the 'subject' is a passive element in the act of cognition (CastroGomez, 2001). This results in a reality that is fragmented.

The mechanistic paradigm approaches problems from a closed systems' perspective, where the life of the 'structure' is considered, while disregarding the subject, reducing problems to 'technical' and removing the barriers for the growth of capital and the maximization of profit (Castro-Gomez, 2001).

The challenges to the mechanistic model are numerous. One of these challenges was launched by the ecological movement at the end of the 1960s as a values-driven social movement (Goldsmith, 1988) to redress the dualistic disconnect between humans and nature as separate entities. The Aristotelian teleological holistic worldview served as a cultural constraint, restraining human activity in respect of the environment. This mutual interdependency was lost with the antianimistic opposition of the dualistic view of creation and reality, where nature was to be 'used' at the service and 'progress' of humanity (Henry, 2008). The environmental movement has increasingly taken 'centre stage', questioning old assumptions about who we are, how we interact with each other, and the ethical conduct of professions vis-àvis the community/environment, including our political and economic structures (Merchant, 2005).

More recently, the concern for global warming, exemplified by the sustainability debate, has rearranged the dynamics of humans from being at the top of the pyramid to the environment as an overarching circle that contains human society and in turn the economy (Mitchell, 2000). Further allies in support of this emerging paradigm are:

The 'deep ecology' philosophy (Naess, 1973) of 'being', where beings cannot be ranked by their relative value, which together with all species become "aspects of a single unfolding order" (Fox, 1990, p252);

The general systems theory (developed in the first half of the $20^{\text {th }}$ century) reinforces the view that various systems maintain and transform themselves as dissipative structures farfrom-equilibrium, viewing the universe as an organised complexity of systems interconnected and interacting (Laszlo, 1987, Prigogine et al., 1984);

Over the last decade, this concept has been further reinforced with the Gaia hypothesis (Lovelock, 2000), where the biosphere and other components of the Earth are closely integrated to form a complex interacting system, viewed as a single organism. This theory (no longer considered as an hypothesis since it has passed predictive tests) reinforced the urgency with which we, as a society, need to redress the expansionist world view, in particular global warming. The health of Gaia together with life on this planet is at great risk. 


\subsection{Sustainability Clarified}

Before exploring the proposition further, a brief look at what is understood by the term sustainability is necessary.

Although widely used, the term "sustainability" remains difficult to define. Dobson (1996) found over 300 different definitions. This could, however, be a good thing, as suggested by Jacobs (1999), where a single universal definition would be counter productive. The best thing one can do is address this ambiguity within the specific context.

For the purpose of this paper, the following sustainability criteria are considered important or at least relevant:

- It is a systemic concept;

- It is concerned with the continuity of environmental, social, economic and institutional aspects of human activity;

- It is concerned with the non-human environment;

- It looks at the means by which present and future needs are met whilst preserving biodiversity and natural ecosystems;

- It focuses on a good quality of life for all humans; and

- All levels of society, from the neighbourhood to the entire planet are concerned and affected.

Recognizing that each community has unique aspirations, as do individuals, the 'onesize fits all' approach would not be recommended as a way forward. What needs to be recognized is that, as a global society, we appear to agree that current practice is not acceptable and that achieving sustainable solutions call for stewardship by the entire environment.

The critical point is that the way of thinking that brought us to the situation we are in now needs to change. Business cannot carry on as usual. We would be fooling ourselves to think that all we need to do is simply adjust current practice.

\subsubsection{Sustainability Requires A New Way Of Thinking}

The aim of this paper is to explore an approach to solve problems in an environment that has shifted from the expansionist mode of production to one of co-existence with the environment. The solution points to design thinking.

To summarise our argument so far - there are numerous converging strands:

- We are in an economic crisis that appears to be changing the relationship between business and society. Reforming the economy might not have traction because people are looking for alternatives. Sustainability will have great influence in the reconfiguration as people lose faith with current formal structures of power and control and the future is complex, fragmented and fluid (Robertson, 1983);

- Quantum theory - describes probabilistic reality, rejection of fundamentalist and positivist notions of knowledge to complementary modes of knowledge. The implications for this are that the world is not necessarily sensible and predictable, where specialists need to embrace the notion of both/and, where certainty and truth are relative and reconstructed actions. Wheeler refers to this as the 'participatory universe' (Bohm et al., 1993);

- Deep Ecology - has been used to criticize modern society and, until recently, was regarded as part of the 'far left'. However, it has now reached a tipping point where people find legitimacy within main stream society to explore and realize their spiritual, aesthetic, ethical, moral needs and concerns, through its notion of wholeness and essence of 'being' (Fry, 2006);

- Sustainable development - as suggested by Walker (2006, p 15), is a "mythic story that attempts to give meaning to some of our principle modern-day uncertainties", mainly "as a socially acceptable, contemporary means of framing our enduring ethical dilemmas and moral choices, as well as our ideas of social justice and environmental stewardship" (p26).

The mechanistic paradigm placed humans at the apex of the universe. This was about creating a new way to generate knowledge (the scientific method) with the objective of improving the human condition. As a society, 
we have been operating under this paradigm for over 350 years. We are now coming to the conclusion that this paradigm, although successful, has destroyed its own foundations (Sagasti, 1990) through the destruction of the environment, bringing us to the realisation that we need to reconsider our links with nature and our dualistic understanding of body and soul.

Paradigms are human constructs. We create them to make sense of the world and to be able to act within it. They are not true in themselves. Theories are necessary for us as a community to collectively organise knowledge, stimulate debate and test.

The reductionist method started to show some 'cracks' when issues and phenomena could not be explained by the methodology. The new set of perspectives, from quantum physics, systems, complexity, chaos to cosmology have led us to create new understandings of ourselves.

We might not have reached the 'new' paradigm as yet. As Walker (2006) suggests the sustainability movement is young. We are at an evolutionary phase, "which embodies a multitude of values and positions and a recognition of the uncertainty of the future and a connection with the past" (Owen, 2003, p49).

This holistic conversion of the relationship between science, philosophy and religion as complementary modes of knowledge, indicates a definite shift in which the experts need to practice, from a narrow to broader domain.

\subsubsection{Not All Experts Have What It Takes}

The problems facing experts are complex or, to use the term by Rittel and Webber (1973), 'wicked'. The implication is how or who is to solve these problems? - we are referring to sustainability-related problems and concerns. Current professions do not inspire confidence due to their reductionist thinking and modes of problem solving and because they operate within silos of interest and knowledge areas.

Sustainability is an emergent property, requiring a holistic perspective, which is in dynamic equilibrium with natural systems (Pearce et al., 1989). It requires a co-created learning systems (Laszlo, 2000) dynamic ap- proach to address the unknown and emergent nature of the issues where the problem boundaries (Cilliers, 2001) are permeable and dynamic.

In an analysis of the engineering profession by Donnelly and Boyle (2006) in relation to their ability to address sustainable development issues, they identify the following as the hindering factors (it is suggested here that this critique applies to a range of experts):

- The solution space occurs at a local 'project' level - implying a relatively impermeable boundary (tending to operate in a closed system view - limiting the scope and other impacted systems);

- Assessment is done on short-term economics perspective;

- Problem framing and solution operates from a specific knowledge paradigm;

- Engineers are considered expert problem solvers, however, they are not known for their problem seeking skills, especially when crossing knowledge domains, such as hard to soft systems or vice versa. Engineers are equally not known for their skills in assessing the impact of their solution (while working on it) to the broader system - they appear to be unable to dynamically operate between the detail and at the macro level - they operate well in one or the other, but not simultaneously in both;

- Engineers are not apt at operating outside the current social, political and institutional arrangements, even though the true sustainable solution will most likely be found outside the prevailing paradigm;

- Another major issue lies within the educational system, which has been in place well over 200 years "and is grounded in mathematics and the physical sciences ... [which] is customized according to specific disciplines (i.e., civil, mechanical, chemical, electrical, environmental, and software, etc.)" (in Donnelly et al., 2006, p.152, Mulder, 2004).

Wicked problems are not easily defined. Their nature changes over time and they are characterized by complex, interacting issues that often emerge as a result of trying to define, understand and resolve the problem. 
Every attempt to solve a wicked problem is neither right nor wrong. What is important is the solution and learning process that a team will often cycle through in their attempts to solve the wicked problem. This co-creation process allows a team to understand the causes of the wicked problem and explain it in numerous ways (Neumeier, c2009'). The effort must be multidisciplinary and over different time frames (short, medium and the long view). The expert, as a product of a selfserving knowledge paradigm, is not able to rise above conventional priorities and business norms, nor is the expert equipped to cope with the demands called for to address sustainable development. As Pink (2005) describes, the left-brain is skilled and comfortable with linear and logical processes, a good match to operate within the scientific method, but not suited for the less structured wicked problems of sustainability.

\subsubsection{Design Thinking Is The Solution}

Leadership, in ensuring that sustainable development solutions are achieved, requires more than technical know-how. People operating in this field require to be systemic thinkers (Checkland, 1981), able to operate within a learning system as the core of the problem dynamic (in terms of change and uncertainty, interaction with others, co-creation of knowledge and perspectives) (Banathy, 1996). They need to be comfortable with and energized by ambiguity, as well as 'design wisdom' (Nelson et al., 2003) as intentional action of purpose and meaning.

If we look at the late Medieval and Renaissance period, we see the practice of solving problems by using philosophy, art, science and technology as an integrated holistic approach to address both clients' and the community's needs. The premise was humanistic and responsive, being able to explore unknown territory and shift perspective.

Pink (2005) suggests that we are entering the 'conceptual age', where creativity, empathy, intuition and the ability to 'link seemingly unrelated objects and events into something new and different is important and necessary'. Taking a closer look at the phrase above, he is really expressing the essence of design thinking and the abilities required to deal with the complexity of sustainable development.

Pink's description of the whole-brain approach captures the synthetic thinking processes of the designer (for a more sophisticated and detailed account refer to Nelson and Stolterman (2003)). However, for the purpose of this paper, Tim Brown's (2008, p87) and Pink's (2005) less exhaustive description will be used:

- Empathy - viewing the world from multiple perspectives - by taking a "people first" approach, design thinkers can imagine solutions that are inherently desirable and meet explicit or latent needs. Great design thinkers observe the world in degrees of detail and patterns. They notice things that others do not and use their insights to inspire innovation;

- Integrative thinking - the whole-brain is used, from analytical processes (either/or choices) to both/and which can sometimes appear to be contradictory aspects of a confounding problem, thereby creating novel solutions (see Roger Martin (2007) for integrative thinking);

- Optimism - tolerance for ambiguity no matter how challenging the constraints of a problem might be;

- Experimentalism - significant innovations don't come from incremental tweaks. Design thinkers pose questions and explore constraints in creative ways that proceed in entirely new directions;

- Collaboration - the complexity of problems has replaced the myth of the lone creative genius with the reality of the enthusiastic interdisciplinary collaborator;

- Synthesis - seeing the big picture, crossing boundaries and being able to combine disparate pieces into a new whole;

- Meaning - purpose, transcendence and spiritual fulfillment;

- Story Telling - the essence of persuasion, communication and self-understanding has become the ability to create a powerful narrative.

The experts that have the skills and training that best address the requirements for leading sustainable development solutions are design 
thinkers. The skills described above are in essence a description of a systems practitioner - design thinking is systemic in nature. All it would take is to train the design thinker in the basic concepts and tools of systems practice, to leverage design's core competency and facilitate the emergence of sustained development.

A second paper will explore a framework to describe design thinking as an emergent property resulting from the complex dynamics of the problem space. This will be done by drawing on the behavior of non-linear complex adaptive systems as self-organizing emergent nature at the edge of chaos and re-interpret the design thinking process in a way which encompasses the intuitive, non-linear and qualitative way in which sustainable development problems need to be addressed.

\subsubsection{Final Thoughts}

Currently, we have the technology that can solve many issues that will address the environmental problems that we are to face. What we need is a radically different creative way to make the changes we need - we need to embrace the long view.

Our way of life has been reductive and deeply analytical - manipulators of selfserving knowledge. We are now shifting as a society, pursuing purpose and meaning, with a need to fill the spiritual vacuum created by our materialistic values of single-minded and selfish pursuit of capital. The age of abundance has left us void of our essence of humanity. We are now looking for something else. The sustainable movement might just be the symptom of the many issues that are converging. The solution we need, will have to address not only to save humanity from a climatic catastrophe, but we also need to relearn being holistic again. In the process, we should not destroy the environment. This realization that we should not destroy the environment is something we forgot, since we did destroy the environment in the past. We must return to a holistic worldview.

We require 'agents of change'. People who can operate and solve problems by learning their way into complex uncharted waters, whilst taking full advantage of the shifts in the market. We need people who can make meaning and develop empathy for the broader environment - social and physical. Our products and services need to be more than just functional and cheap - they need to embody our changing values and needs. We have not been fulfilled by prosperity. The paradox of prosperity is that while living standards have increased, we are not happier as individuals, families or as a society. That is why the market which is slowly being liberated from materialism is now resolving the paradox, by searching for meaning, and sustainability might be that all encompassing representation of a new paradigm. Andrew Delbanco (1999) suggests that contemporary culture has lost its purpose. It needs to rededicate itself to a new story of transcendence.

People are seeking something - this "something" is to have a sustainable society, where the issues that are faced are not treated in a "one-size fits all" attitude, but instead, specific consideration and recognition results in an understanding that each situation is unique, since all contexts are different. This change in understanding implies that recognition is given to a set of values that were disregarded or suppressed. Now these values play an important role due to the changing attitudes towards the way we see the world and our role in it. We have moved from being 'mechanistic' to 'human', where altruistic care (for the environment and other humans) is not selfish and only looking after the self, but caring for others. This altruistic care is important as it indicates the values underpinning the shift in attitude required for sustainability to work.

\section{Conclusion}

The paper explored the nature of knowledge creation under the mechanistic paradigm as reductionist and self-serving. Most professionals/experts still operate under this worldview.

By looking at the engineering profession as an example, a detailed list describes why most professionals are not able to operate in a more complex and dynamic context required by the problem space of sustainable development. 
The paper briefly surveys the literature to describe the reasons for a shift from the mechanistic worldview to the new era, which has been described as 'the conceptual age'. This new worldview is driven in current society by disillusion with materialism and the selfish pursuit of capital.

The paper suggests that sustainable development is systemic in nature and must be approached by experts who are primarily systems thinkers. The proposal that design thinking is a naturally systemic process and these experts should be leading in solving the wicked problems of sustainable development is the central focus of this paper.

\section{References}

Banathy, B. H. (1996). Designing social systems in a changing world. New York: Plenum Press.

Berman, M (1981). The Reenchantment of the World. Ithaca, London: Cornell University Press.

Bohm, D. \& Hiley, B. J. (1993). The Undivided Universe: an ontological interpretation of quantum theory. London: Routledge.

Brown, T. (2008). Design Thinking. Harvard Business Review, 86 (6), 84-92.

Castro-Gomez, S. (2001). Traditional vs. Critical Cultural Theory. Cultural Critique, 49, 139-154.

Checkland, P. (1981). Systems thinking, systems practice. Chichester: Wiley.

Cilliers, P. (2001). Boundaries, Hierarchies and Networks in Complex Systems. International Journal of Innovation Management, 5 (2), 135-147.

Delbanco, A. (1999). The real American dream: a meditation on hope. Cambridge, London: Harvard University Press.

Dobson, A. (1996). Environment sustainabilities: An analysis and a typology. Environmental Politics, 5 (3), 401-428.

Donnelly, R. \& Boyle, C. (2006). The Catch-22 of Engineering Sustainable Development. Journal of Environmental Engineering, 132 (2), 149-155.

Foucault, M. \& Gordon, C. (1980). Power/knowledge: selected interviews and other writings. 1972-1977. Brighton, Sussex: Harvester Press.

Fox, W. (1990). Toward a Transpersonal Ecology: developing new foundations for environmentalism. Boston, Shambhala: Random House.

Fry, T. (2006). Design, Ethics \& Identity. Design Philosophy Papers. 1-12. [Online]. Available at: http://www.desphilosophy.com/dpp/home.html (Accessed: 14 April 2009).

Goldsmith, E. (1988). Gaia: some implications of theoretical ecology. The Ecologist, 18 (2/3), 64-74.

Henry, J. (2008). The scientific revolution and the origins of modern science. Basingstoke: Palgrave Macmillan.

Jacobs, M. (1999) Sustainable development as a contested concept. In A. Dobson (Ed.), Fairness and futurity: essays on environmental sustainability and social justice. Oxford: Oxford University Press.

Kuhn, T. S., Conant, J. \& Haugeland, J. (2000). The Road Since Structure: Philosophical Essays. 1970-1993. Chicago, London: University of Chicago Press.

Laszlo, E. (1987). Evolution: the grand synthesis. Boston: New Science Library.

Laszlo, K. C. \& Laszlo, A. (2000). 'Learning to Become: Creating Evolutionary Learning Community through Evolutionary Systems Design'. A Coalition for Self-Learning. Available at: http://www.creatinglearningcommunities.org/book/roots/laszlo2.htm (Accessed: 28 April 2009).

Leiss, W. (1994). The Domination of Nature. Montreal, Buffalo: McGill-Queen's University Press.

Lovelock, J. (2000). Homage to Gaia: the life of an independent scientist. Oxford: Oxford University Press.

Martin, R. L. (2007). The Opposable Mind: how successful leaders win through integrative thinking. Boston: Harvard Business School Press.

Merchant, C. (2005). Radical ecology: the search for a livable world. New York, London: Routledge.

Mitchell, C. (2000). Integrating Sustainability in Chemical Engineering Practice and Education: Concentricity and its Consequences. Process Safety and Environmental Protection, 78 (4), 237-242.

Mulder, K. (2004). Engineering Education in Sustainable Development: sustainability as a tool to open up the windows of engineering institutions. Business Strategy and the Environment, 13 (4), 275-285.

Naess, A. (1973). The shallow and the deep, long-range ecology movement. A summary. Inquiry, 16 (1), 95 - 100.

Nelson, H. G. \& Stolterman, E. (2003). The Design Way: intentional change in an unpredictable world: foundations and fundamentals of design competence. Englewood Cliffs: Educational Technology Publications.

Neumeier, M. (2009). The designful company: how to build a culture of nonstop innovation: a whiteboard overview. Berkeley: New Riders.

Owen, C. (2003). The Green field: the sub culture of sustainable architecture. PhD thesis: Melbourne University. 
Pearce, D. W., Markandya, A. \& Barbier, E. B. (1989). Blueprint for a green economy. London: Earthscan.

Pink, D. H. (2005). A whole new mind: moving from the information age to the conceptual age. Crows Nest: Allen \& Unwin. Prigogine, I. \& Stengers, I. (1984). Order out of Chaos: man's new dialogue with nature. Toronto, New York: Bantam Books. Rittel, H. W. J. \& Webber, M. M. (1973). Dilemmas in a General Theory of Planning. Policy Sciences. Elsevier, 4, 155-169. Robertson, J. (1983). The Sane Alternative: a choice of futures. St. Paul: Minn.

Sagasti, F. R. (1990.) International cooperation in a fractured global order. Impact of Science on Society, 39 (3), 207-211. Seitz, F. (1992). The science matrix: the journey, travails, triumphs. Springer.

Shapin, S. (1996). The Scientific Revolution. Chicago: University of Chicago Press.

Shapin, S. (2008). The Scientific Life: A Moral History of a Late Modern Vocation. Chicago, London: University of Chicago Press.

Walker, S. (2006). Sustainable by design: explorations in theory and practice. London: Earthscan.

\section{About the Author}

Rui Martins is a design strategist and a consultant in team excellence and organizational training. With over 20 years' experience, Rui approaches complex problems from the perspective of long-term sustainability. He has advised organizations on the value of user-centered design and the creation of products/brands/services to improve the company's ability to seize new market opportunities. He is a passionate innovator with a proven ability to inspire and lead high-performance, crossdisciplinary teams in the creation of groundbreaking solutions in complex environments. Rui has experience in a variety of industries such as: Business \& Strategy; Tourism; Construction; Architecture; Manufacturing; Central Government; Local Government and Tertiary Education. Rui has won various awards and competitions in the design field and has published in project management, organizational learning and complexity. He is company director for EarthPlea. 